\title{
Orthodontic bonding to silicate ceramics: impact of different pretreatment methods on shear bond strength between ceramic restorations and ceramic brackets
}

\author{
Rebecca Jungbauer ${ }^{1,2}$ (D) $\cdot$ Christian Kirschneck ${ }^{1} \cdot$ Christian M. Hammer $^{3} \cdot$ Peter Proff $^{1} \cdot$ Daniel Edelhoff $^{2}$. \\ Bogna Stawarczyk ${ }^{2}$
}

Received: 18 July 2021 / Accepted: 23 October 2021 / Published online: 18 November 2021

(C) The Author(s) 2021

\begin{abstract}
Objective The study aims to investigate the shear bond strength (SBS) between silicate ceramic restorations and ceramic brackets after different pretreatments and aging methods.

Material and methods Leucite (LEU) and lithium disilicate (LiSi) specimens were pretreated with (i) $4 \%$ hydrofluoric acid + silane (HF), (ii) Monobond Etch\&Prime (MEP), (iii) silicatization + silane (CoJet), and (iv) SiC grinder + silane (SiC). Molars etched (phosphoric acid) and conditioned acted as comparison group. SBS was measured after $24 \mathrm{~h}$ (distilled water, $\left.37^{\circ} \mathrm{C}\right), 500 \times$ thermocycling $\left(5 / 55^{\circ} \mathrm{C}\right.$ ), and 90 days (distilled water, $37^{\circ} \mathrm{C}$ ). Data was analyzed using Shapiro-Wilk, Kruskal-Wallis with Dunn's post hoc test and Bonferroni correction, Mann-Whitney $U$, and $\mathrm{Chi}^{2}$ test $(p<0.05)$. The adhesive remnant index (ARI) was determined.

Results LEU pretreated with MEP showed lower SBS than pretreated with HF, CoJet, or SiC. LiSi pretreated with MEP resulted in lower initial SBS than pretreated with HF or SiC. After thermocycling, pretreatment using MEP led to lower SBS than with CoJet. Within LiSi group, after 90 days, the pretreatment using SiC resulted in lowest SBS values. After HF and MEP pretreatment, LEU showed lower initial SBS than LiSi. After 90 days of water storage, within specimens pretreated using CoJet or SiC showed LEU higher SBS than LiSi. Enamel presented higher or comparable SBS values to LEU and $\mathrm{LiSi}$. With exception of MEP pretreatment, ARI 3 was predominantly observed, regardless the substrate, pretreatment, and aging level.
\end{abstract}

Conclusions MEP pretreatment presented the lowest SBS values, regardless the silicate ceramic and aging level. Further research is necessary.

Clinical relevance There is no need for intraoral application of HF for orthodontic treatment.

Keywords Silicate ceramic $\cdot$ Orthodontic bonding $\cdot$ Shear bond strength $\cdot$ Ceramic bracket $\cdot$ Pretreatment

\section{Introduction}

Rebecca Jungbauer

Rebecca.jungbauer@ukr.de

1 Department of Orthodontics, University Medical Centre Regensburg, Regensburg, Germany

2 Department of Prosthetic Dentistry, University Hospital, LMU Munich, Germany

3 Institute of Functional and Clinical Anatomy, Friedrich Alexander University Erlangen-Nürnberg, Erlangen, Germany
The number of adult patients asking for orthodontic treatment is steadily increasing $[1,2]$. In many cases treatment with fixed appliances is necessary to accomplish a fully controlled movement of the teeth in all three dimensions. Therefore, brackets need to be bonded temporarily to the enamel surface after a combination of etching using 35\% phosphoric acid and conditioning using an adhesive system. The recommended bond strength in the literature is $5-10 \mathrm{MPa}$ [3]. In those cases, where patients present with existing dental restorations, the orthodontist needs a reliable treatment protocol 
for bonding brackets to artificial surfaces, in many cases tooth colored restorations such as reinforced (lithium silicate, LiSi) and low reinforced silicate (leucite, LEU) ceramics. Both type of ceramics are silicate ceramics, which have a very high translucency compared to zirconia ceramic and are therefore very esthetic $[4,5]$. Lithium silicate ceramics show higher flexural strength and fracture toughness compared to leucite-based ceramics, based on the higher volume fraction of crystals and therefore a tighter interlocking matrix of the silicate-based materials [6-8]. An interaction between the bonding material and the microporosity of the ceramic is determined by the capability of the resin cement to wet the ceramic surface, dependent on the surface chemistry and roughness of the ceramic as well as the viscosity and composition of the bonding material [9-11]. The surface roughness of the ceramic is affected by etching or mechanical treatment. During orthodontic treatment the number of accidental bracket losses must be kept to a minimum, but at the same time the silicate ceramic surface should not be damaged when brackets are removed after active treatment $[12,13]$. In the literature the intraoral application of 5-9\% hydrofluoric acid (HF) for orthodontic purposes for $60 \mathrm{~s}$ in combination with the use of a silane is often described to prepare silicate surfaces and create micromechanical and chemical retention for bonding brackets [14-22]. The general recommendation is to etch only low reinforced silicate ceramics for $60 \mathrm{~s}$ with HF. In contrast, reinforced ceramics such as lithium silicate ceramics should only be etched for $20-30 \mathrm{~s}$ [23]. This reinforced ceramic contains less glass phase for the HF etching process. Therefore, with longer etching treatment times, the surface becomes smoother again, resulting in reduced adhesion. Due to the different etching times of silicate ceramic types, the practitioner needs to know which type of ceramic is present to attach the brackets to. Apart from this procedure being very time consuming [24], HF is known to be very toxic and can cause various hazardous effects for both the patient and even more the clinician who deals with HF more frequently [25-28]. Nevertheless, the application of HF seems to be the actual gold standard to prepare silicate ceramic surfaces to bond brackets [22, 29]. From the clinician's point of view an all-in-one pretreatment with a reduced hazard potential for patients and clinicians, such as Monobond Etch\&Prime (MEP), would be desirable for bonding brackets to silicate ceramic restorations. Furthermore, different pretreatment methods, which are used in restorative and prosthetic dentistry for intraoral reparation of silicate ceramic restorations without the application of any acids, are viable options for orthodontic purposes. These comprise mechanical roughening of the surface with silicium carbide $(\mathrm{SiC})$ grinders or chemical/mechanical pretreatment with intraoral silicate coating (CoJet) [30-32]. According to the DIN 13,990:2017-04 testing the SBS values after 500 thermal cycles is recommended additional to the initial ones [33]. Therefore, the aim of this study was to investigate the shear bond strength of ceramic brackets and two types of silicate ceramic surfaces after different pretreatment methods. The assumed hypotheses were that (1) the pretreatment of the silicate ceramic, (2) the aging level, and (3) the choice of silicate ceramic show no impact on shear bond strength values.

\section{Materials and methods}

\section{Specimen preparation}

One-hundred-eighty square specimens were cut into slices of 3-mm thickness with a low-speed diamond saw under constant water application (Secotom-50, Struers, Ballerup, Denmark) from lithium disilicate blanks (LiSi, IPS e.max CAD A2/C14, Ivoclar Vivadent, Schaan, Liechtenstein). LiSi specimens in the purple state underwent a specific treatment for final crystallization (program IPS e.max CAD Crystal/Glaze HT/LT, furnace: Programat EP 5000, Ivoclar Vivadent; Table 1). The 180 leucite ceramic specimens (LEU, VITA VM 13, VITA, Bad Säckingen, Germany) were fabricated using layering technique. To achieve standardized size of the specimens, a silicone key was used. In a second firing, under the same conditions, dentin was added to compensate for the shrinkage of the sintering process. Prior to the second firing (Austromat 654, preee-i-dent, Dekema, Freilassing, Germany; Table 1), the slurry was condensed into the mold using a vibrator for $2 \mathrm{~s}$ at $50 \mathrm{~Hz}$ (ElektroVibrator Porex, Renfert, Hilzingen, Germany).

Thereafter, all 360 specimens were embedded in acrylic resin (ScandiQuick A and B; Scan-Dia, Hagen, Germany) and polished up to P2000 (SiC paper; Struers) with an automatic polishing machine (Tegramin 20, Struers) under continuous water-cooling. The specimens were randomly assigned to one of the 12 subgroups, resulting in 24 groups (15 specimens in each group in accordance with previous
Table 1 Firing schedules of the ceramics

\begin{tabular}{|c|c|c|c|c|c|c|}
\hline \multirow[t]{2}{*}{ Veneering ceramic } & \multicolumn{2}{|l|}{ Pre drying } & \multirow{2}{*}{$\begin{array}{l}\text { Heating rate } \\
\left({ }^{\circ} \mathrm{C} / \mathrm{min}\right)\end{array}$} & \multirow{2}{*}{$\begin{array}{l}\text { Firing tem- } \\
\text { perature }\left({ }^{\circ} \mathrm{C}\right)\end{array}$} & \multirow{2}{*}{$\begin{array}{l}\text { Holding } \\
\text { time (min) }\end{array}$} & \multirow{2}{*}{$\begin{array}{l}\text { Vacuum } \\
\text { during } \\
\text { heating }\end{array}$} \\
\hline & $\begin{array}{l}\text { Tempera- } \\
\text { ture }\left({ }^{\circ} \mathrm{C}\right)\end{array}$ & Time (min) & & & & \\
\hline VITA VM13 & 500 & 6 & 55 & 890 & 1 & Yes \\
\hline IPS e-max CAD & 403 & 6 & 60 & 850 & 10 & Yes \\
\hline
\end{tabular}


studies [34-37]). As comparison and to be able to quantify the SBS value, 45 human third molars free of caries and restorations were collected after extraction, stored in $0.5 \%$ chloramine-T solution (Sigma-Aldrich Laborchemikalien, Seelze, Germany; Lot No. 53110) for 1 week at room temperature, and stored in distilled water at $5{ }^{\circ} \mathrm{C}$ for a maximum of 6 months. They were fixed with the buccal side up and parallel to the base with dental technician wax and embedded in the acrylic resin (ScandiQuick A and B). The collection and use of human teeth extracted for medical reasons was approved by the ethics committee of the University of Regensburg, Germany (12-170-0150). All methods were carried out according to relevant regulations and guidelines. From all participants or their parent/legal guardian informed consent was obtained.

\section{Ceramic pretreatment and bracket bonding}

Before pretreatment, all specimens were scrubbed with a pumice/water mixture (40 g:50 g) and a polishing brush (Busch \& Co., Engelskirchen, Germany) for 3 s moving from left to right and $3 \mathrm{~s}$ up and down at a speed of 3000 rounds per minute. Afterward the pumice was rinsed off with water. Depending on the group the ceramic surface was pretreated as shown in Fig. 1. The third molars were conditioned with
$35 \%$ phosphoric acid (iBond Etch, Kulzer, Hanau) for $30 \mathrm{~s}$ before rinsing off the acid with water and gently air drying until a frosty surface was visible. A thin layer of Transbond XT Primer ( $3 \mathrm{M}$, Monrovia, USA) was applied to the surface and gently dispersed with compressed air. The ceramic brackets (Clarity Advanced, $3 \mathrm{M}$, Monrovia, USA) were bonded directly to each specimen.

After placing the bracket, gentle pressure was applied to keep the interface of the attachment material to a minimum. Excess was removed carefully with a dental probe before $3 \mathrm{~s}$ of light-curing $\left(1600 \mathrm{~mW} / \mathrm{cm}^{2}\right.$, Ortholux luminous curing light, $3 \mathrm{M}$, Monrovia, USA) through the center of the ceramic bracket. After the bonding procedure, all specimens were directly stored in distilled water. Shear bond strength was tested either after $24 \mathrm{~h}$ wet storage in distilled water at $37^{\circ} \mathrm{C}$ (baseline/initial), 500 thermal cycles $\left(5 / 55^{\circ} \mathrm{C}\right.$, dwelling time: $20 \mathrm{~s}$, Thermocycler THE 1100, SD Mechatronik, Feldkirchen-Westerham, Germany), or 90 days wet storage in distilled water at $37^{\circ} \mathrm{C}$. Detailed information on materials used is given in Table 2 .

\section{Shear bond strength testing}

Before testing all specimens were stored in distilled water at room temperature for $1 \mathrm{~h}$ and shear bond strength was

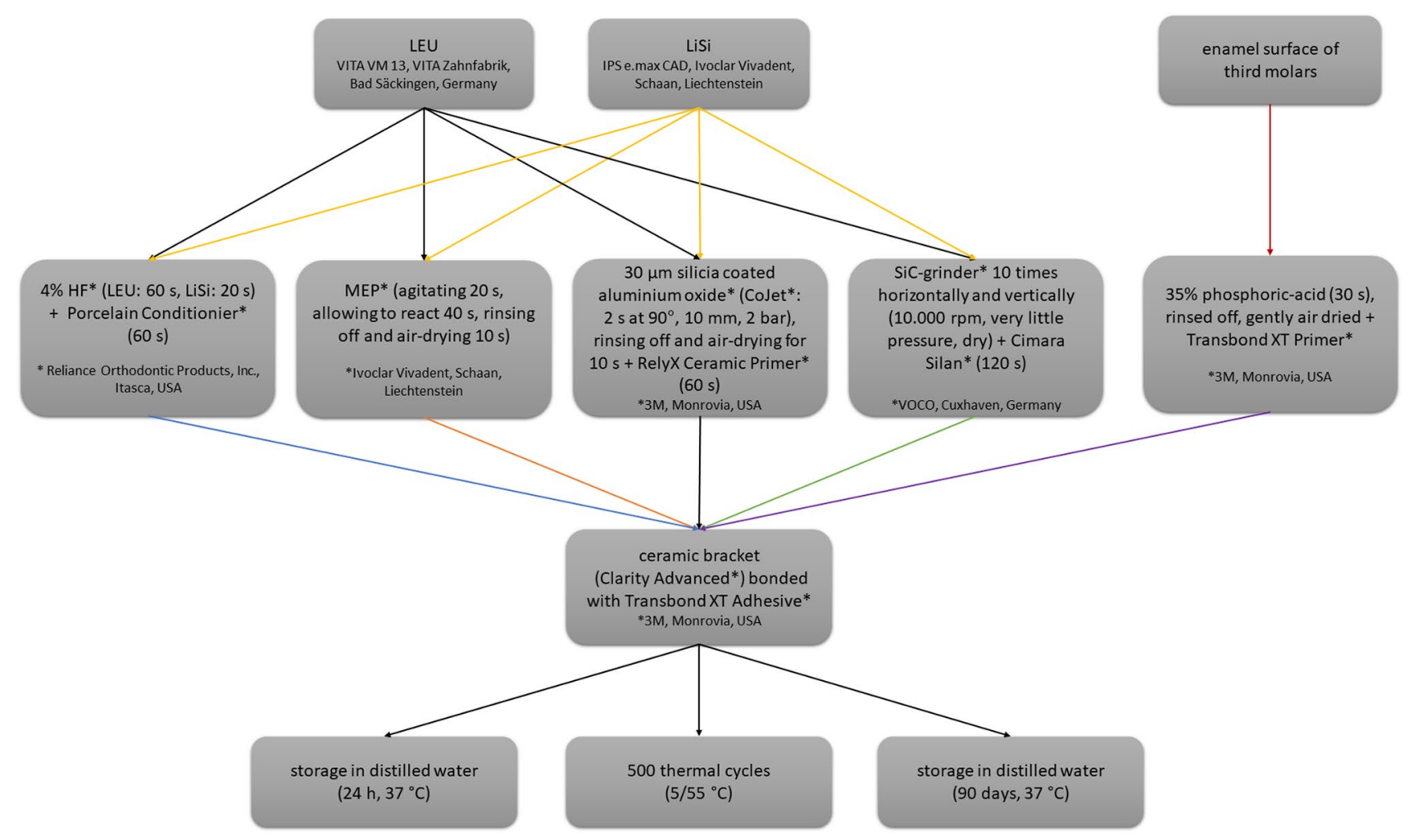

Fig. 1 Study workflow. The flowchart presents the pretreatment of the two different ceramic and enamel specimens. $L E U$ leucite, $L i S i$ lithium disilicate, $H F$ hydrofluoric acid, $M E P$ Monobond Etch\&Prime, $S i C$ grinder silicium carbide grinder 
Table 2 Manufacturer and composition of the luting materials employed in this study

\begin{tabular}{lll}
\hline Materials & Manufacturer & Composition \\
\hline $\begin{array}{l}\text { PorcEtch (HF) } \\
\text { Porcelain conditioner }\end{array}$ & $\begin{array}{l}\text { Reliance Orthodontic Products } \\
\text { Reliance Orthodontic Products }\end{array}$ & $\begin{array}{l}\text { Hydrofluoric acid (7\%), aqueous solutions, sodium fluoride } \\
\text { Ethanol/denatured, 3-(trimethoxysilyl)propyl-2-methyl-2-propenoic acid, acetic } \\
\text { acid } \\
\text { Tetrabutyl ammonium dihydrogen trifluoride, methacrylated phosphoric-acid } \\
\text { ester, trimethoxysilylpropyl methacrylate, alcohol, water }\end{array}$ \\
$\begin{array}{l}\text { RelyX Ceramic Primer } \\
\text { Cimara Silan }\end{array}$ & $3 \mathrm{M}$ & $\begin{array}{l}\text { Ethl alcohol, water, methacryloxypropyltrimethoxysilane } \\
\text { Mixture of various dimethacrylates, initiators, 2-propanol, silicates, additives }\end{array}$ \\
TransbondXT primer & VOCO & $\begin{array}{l}\text { Bis-GMA, TEGDMA, triphenylantimony, 4-(dimethylamino)-benzeneethanol, } \\
\text { DL-camphorquinone, hydroquinone }\end{array}$ \\
TransbondXT adhesive & $3 \mathrm{M}$ & $\begin{array}{c}\text { Silane-treated quartz, Bis-GMA, EBPADMA, silane-treated silica, diphnyli- } \\
\text { odonium hexafluorophosphate }\end{array}$ \\
\end{tabular}

Bis-GMA bisphenol-A-diglycidyl ether dimethacrylate, TEGDMA triethylene glycol dimethacrylate, EBPADMA bisphenol-A-bis(2-hydroxyethyl ether) dimethacrylate

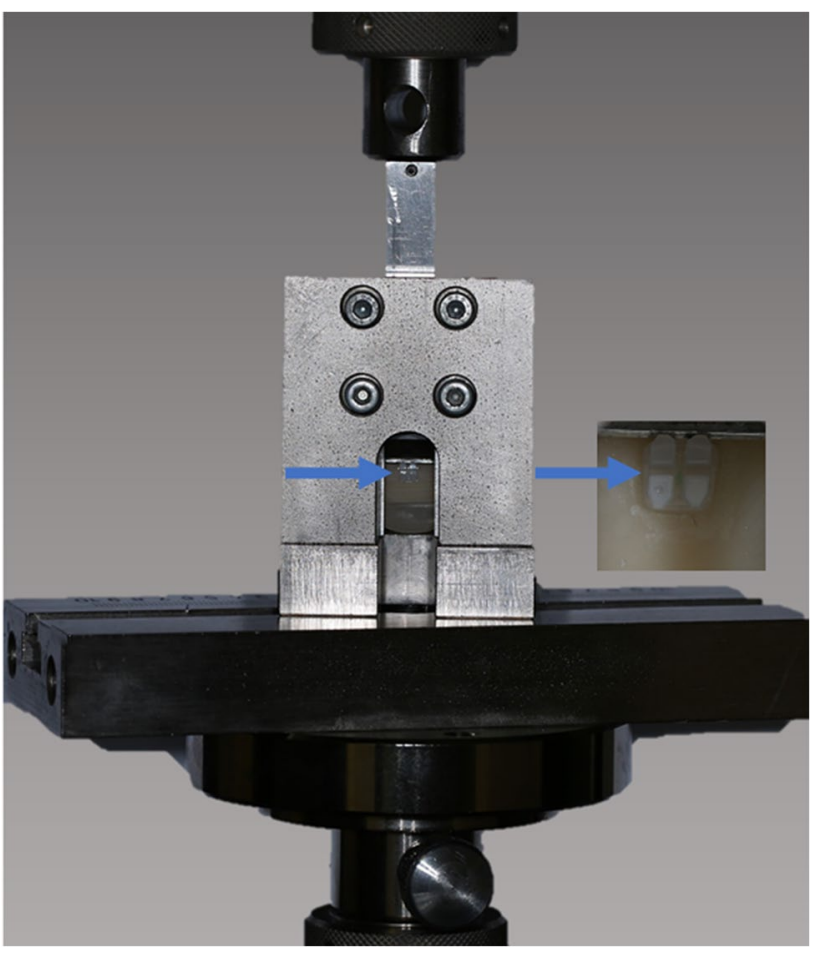

Fig. 2 Experimental setup for SBS measurements. The specimen with the bonded bracket (arrow and in higher magnification) is fixed in the test apparatus and placed in the universal testing machine. The force is applied in an occlusal-gingival direction (downward) and recorded simultaneously

tested at room temperature $\left(23{ }^{\circ} \mathrm{C}\right)$. The gently dried specimens were placed in a specially designed test apparatus (Fig. 2) in the universal testing machine (RetroLine, Zwick/Roell, Ulm, Germany). The compressive force was applied perpendicularly to the specimen surface in an occluso-gingival direction with a crosshead speed of
$1 \mathrm{~mm} / \mathrm{min}$ until fracture. The maximum force was recorded in Newton and the area of the bracket was given by the manufacturer. SBS was calculated using the formula:

$\mathrm{R}(\mathrm{N} / \mathrm{mm} 2)=\frac{F(N)}{A\left(\mathrm{~mm}^{2}\right)}$

After the SBS testing, all specimens were photographed using a microscope with $10 \times$ magnification (Bresser, Rhede, Germany) to search for cracks and to determine the adhesive remnant index (ARI). ARI was evaluated as follows: $0=$ no remaining attachment material (AM) on the ceramic, $1=$ less than $50 \%$ remaining on the ceramic, $2=$ more than $50 \%$ remaining on the ceramic, and $3=100 \%$ AM remaining on the ceramic [38]. Additionally, seven specimens were viewed with a JEOL scanning electron microscope at $30 \times$ and $250 \times$ magnification (JSM-IT 300LV, JEOL Germany, Eching, Germany) after sputter-coating with a 20-nm layer of gold using the Leica EM ACE200 system (Leica Mikrosysteme, Vienna, Austria).

\section{Reliability of measurements}

To assess intrarater and interrater reliability of the ARI the Cohen's kappa coefficient $(\kappa)$ was calculated. Therefore, 20 specimens were selected to determine the ARI a second time by the same investigator and additionally by a second experienced investigator.

\section{Statistical methods}

The software IBM SPSS Statistics 23 (IBM, Armonk, NY, USA) was used for statistical analysis. For the descriptive statistic medians (MD), interquartile ranges (IQR) as well as minimum (MIN) and maximum (MAX) were reported. 
According to a Shapiro-Wilk test and visual assessment of the histograms more than $5 \%$ of the data were not distributed normally. Therefore, non-parametric Kruskal-Wallis tests by ranks, followed by pairwise comparison Dunn's post hoc tests with $p$-value Bonferroni correction and Mann-Whitney $U$ tests were applied to check the differences between groups for statistical significance. The $\mathrm{Chi}^{2}$ test was used to evaluate the ARI. $P$ values $\leq 0.05$ were considered as statistically significant.

\section{Results}

\section{Influence of pretreatment}

Within LEU ceramic, MEP pretreatment (23.2 $\mathrm{MPa}$ ) presented lower initial SBS than CoJet (37.0 MPa, $p=0.001$ ) or $\mathrm{SiC}(40.9 \mathrm{MPa}, p<0.001)$. After aging of 500 thermal cycles, MEP pretreatment $(17.7 \mathrm{MPa})$ resulted in lower SBS values compared to $\mathrm{HF}$ (33.7 MPa, $p=0.005)$, CoJet (40.6 MPa, $p<0.001$ ), and $\mathrm{SiC}$ (35.3 MPa, $p<0.001$; Table 3).

Within LiSi ceramic, pretreatment with MEP (35.7 MPa) resulted in lower initial SBS values than pretreatment with $\mathrm{HF}$ (40.4 MPa, $p=0.032$ ) and $\mathrm{SiC}$ (42.3 MPa, $p=0.013$ ). After 500 thermal cycles, pretreatment with $\operatorname{MEP}(15.2 \mathrm{MPa})$ led to lower SBS values than with CoJet pretreated ones (36.3 MPa, $p=0.007$ ). After 90 days of storage, pretreatment with $\mathrm{SiC}$ resulted in lower SBS values $(0.4 \mathrm{MPa})$ compared to remaining pretreatment methods (HF: $33.7 \mathrm{MPa}, \mathrm{MEP}$ : 30.2 MPa, CoJet: 19.0 MPa; $p<0.001)$.

\section{Influence of artificial aging}

Within the LEU/MEP group, 90 days of wet storage (33.3 $\mathrm{MPa}$ ) resulted in higher SBS values compared to 500 thermal cycles $(17.7 \mathrm{MPa}, p=0.002)$. For CoJet pretreatment, SBS values were lower after 90 days of storage (31.6 MPa) than the initial (37.0 MPa, $p=0.032)$ and after 500 thermal cycles (40.6 MPa, $p=0.008$ ).

For LiSi combined with MEP pretreatment, 500 thermal cycles (15.2 MPa) presented lower SBS values compared to initial ones (35.7 MPa, $p=0.021)$. For CoJet and SiC pretreatment, 90 days of storage resulted in lower SBS values in comparison to the baseline (CoJet: 90 days: $19.0 \mathrm{MPa}$ and initial: $39.7 \mathrm{MPa}, p<0.001$; SiC: 90 days: 0.4 MPa and initial: $42.3 \mathrm{MPa}, p<0.001)$.

\section{Influence of ceramic}

Within HF and MEP pretreatment, LEU showed lower initial SBS values (HF: 33.6 MPa, MEP: 23.2 MPa) than LiSi (HF: 40.4 MPa, $p=0.023$ and MEP: $35.7 \mathrm{MPa}, p=0.003$ ). After 90 days of wet storage and CoJet (LEU: $31.6 \mathrm{MPa}$ and LiSi: 19.0 MPa, $p=0.004$ ) and $\mathrm{SiC}$ pretreatment (LEU: $35.2 \mathrm{MPa}$ and LiSi: 0.4 MPa, $p<0.001)$ presented LEU higher SBS compared to LiSi.
Table 3 Non-parametric descriptive statistics including median, interquartile range (IQR), minimum (Min), and maximum (Max). All values are in MPa

\begin{tabular}{|c|c|c|c|c|c|c|c|c|c|}
\hline \multirow[t]{2}{*}{ Pretreatment } & \multirow[t]{2}{*}{ Aging } & \multicolumn{4}{|l|}{ LEU } & \multicolumn{4}{|l|}{$\mathrm{LiSi}$} \\
\hline & & Median & IQR & Min & $\operatorname{Max}$ & Median & IQR & Min & $\operatorname{Max}$ \\
\hline $\mathrm{HF}$ & $24 \mathrm{~h}$ & $33.6^{\mathrm{ab}, \mathrm{A}, 1}$ & 11.7 & 18.5 & 53.4 & $40.4^{\mathrm{a}, \mathrm{B}, 1}$ & 17.1 & 28.8 & 59.4 \\
\hline MEP & & $23.2^{\mathrm{a}, \mathrm{C}, 2,3}$ & 7.5 & 10.2 & 41.4 & $35.7^{\mathrm{b}, \mathrm{D}, 2}$ & 13,7 & 12.7 & 48.5 \\
\hline CoJet & & $37.0^{\mathrm{b}, \mathrm{E}, 4}$ & 15.5 & 7.7 & 53.7 & $39.7^{\mathrm{ab}, \mathrm{E}, 4}$ & 8.0 & 29.2 & 56.2 \\
\hline $\mathrm{SiC}$ & & $40.9^{\mathrm{b}, \mathrm{F}, 6}$ & 16.0 & 29.3 & 52.7 & $42.3^{\mathrm{a}, \mathrm{F}, 6}$ & 16.1 & 30.4 & 61.8 \\
\hline $\mathrm{HF}$ & $500 \mathrm{TC}$ & $33.7^{\mathrm{c}, \mathrm{A}, 1}$ & 14.2 & 14.8 & 48.6 & $37.0 \mathrm{~cd}^{\mathrm{A}, 1}$ & 13.3 & 13.0 & 47.8 \\
\hline MEP & & $17.7^{\mathrm{d}, \mathrm{B}, 2}$ & 9.6 & 12.4 & 32.1 & $15.2^{\mathrm{c}, \mathrm{B}, 3}$ & 22.9 & 4.4 & 43.4 \\
\hline CoJet & & $40.6^{\mathrm{c}, \mathrm{C}, 4}$ & 11.8 & 27.6 & 53.1 & $36.3^{\mathrm{d}, \mathrm{C}, 4}$ & 16.5 & 27.3 & 60.5 \\
\hline $\mathrm{SiC}$ & & $35.3^{\mathrm{c}, \mathrm{D}, 6}$ & 20.0 & 20.1 & 57.3 & $32.1 \mathrm{~cd}^{\text {D, }} 6$ & 41.9 & 0.0 & 60.2 \\
\hline $\mathrm{HF}$ & 90 days & $32.6^{\mathrm{e}, \mathrm{A}, 1}$ & 14.8 & 17.3 & 41.9 & $33.7^{\mathrm{e}, \mathrm{A}, 1}$ & 14.4 & 19.4 & 59.4 \\
\hline MEP & & $33.3^{\mathrm{e}, \mathrm{B}, 3}$ & 21.7 & 15.8 & 55.9 & $30.2^{\mathrm{e}, \mathrm{B}, 2,3}$ & 9.7 & 19.9 & 43.6 \\
\hline CoJet & & $31.6^{\mathrm{e}, \mathrm{C}, 5}$ & 12.2 & 18.1 & 38.5 & $19.0^{\mathrm{e}, \mathrm{D}, 5}$ & 16.1 & 8.6 & 35.5 \\
\hline $\mathrm{SiC}$ & & $35.2^{\mathrm{e}, \mathrm{E}, 6}$ & 21.5 & 9.6 & 48.2 & $0.40^{\mathrm{f}, \mathrm{F}, 7}$ & 4.4 & 0.0 & 5.8 \\
\hline
\end{tabular}

Different lowercase letters indicate significant differences within the aging groups ( $24 \mathrm{~h}, 500 \mathrm{TC}, 90$ days) after different pretreatments in the columns, different uppercase letters indicate significant differences in the raw, and different numbers indicate significant differences within the pretreatment groups (HF, MEP, CoJet, SiC) after different aging methods in the columns. $H F$ hydrofluoric acid, MEP Monobond Etch\&Prime, $\mathrm{SiC}$ silicium carbide grinder, $T C$ thermal cycling 


\section{Bonding to enamel}

The initial SBS value was the highest (54.0 MPa) and was reduced to $39.8 \mathrm{MPa}$ and $33.3 \mathrm{MPa}$ after 500 thermal cycles and 90 days of storage, respectively.

\section{Adhesive remnant index (ARI)}

On the LEU surface an ARI 3 was most frequent after pretreatment with $\mathrm{HF}$, CoJet, and $\mathrm{SiC}(95.6 \%, 86.7 \%, 73.3 \%)$. ARI 0 was not detected. After pretreatment with MEP on $42.2 \%$ no adhesive, and $33.3 \%$ more than $50 \%$ remained on the surface.

After pretreatment of LiSi with HF and CoJet an ARI 3 was the most common $(77.8 \%, 51.1 \%)$. The pretreatment with MEP resulted in an evenly distributed frequency of ARI 0,1 , and 3. In the $\mathrm{SiC}$ group none of the attachment material remained on the surface after $\mathrm{SiC}$ pretreatment (51.1\%), followed by less than $50 \%$ (26.7\%). On the enamel surface all the attachment material was present in $42.2 \%$ (Table 4).

Scanning electron microscopic images of the bonding surface on the ceramic or enamel after the SBS measurement are displayed in Fig. 3. The trapezoidal bonding area was easily discernible in all specimens.

\section{Reliability of measurements}

The intrarater and the interrater reliability ARI assessment were both almost perfect $(\kappa=0.85)$ [39].

\section{Discussion}

The aim of this in-vitro investigation was to test the SBS of ceramic brackets bonded to two different types of silicate ceramic after four different pretreatment methods and after different aging methods. The first hypothesis ("the pretreatment of the silicate ceramic shows no impact on SBS values") had to be rejected, as pretreatment with MEP resulted in lower SBS values after $24 \mathrm{~h}$ and 500 thermal cycles, with a difference in the LiSi group after $24 \mathrm{~h}$ and in LEU group after 500 thermal cycles. After 90 days of wet storage, there were lower SBS values after pretreatment of LiSi with SiC. In the literature HF still seems to be considered as the gold standard for bonding brackets to silicate ceramic [22, 29]. However, the intraoral application of HF might be associated with some risk factors since it is known to be very toxic and hazardous. Furthermore, the different etching times for LEU and LiSi should be considered and presuppose that the clinician/patient knows the type of material used for the restoration. MEP combines the hydrofluoric-acid etching and silanization steps and contains ammonium polyfluoride for the etching effect and trimethoxypropyl methacrylate for silanization. When comparing the etching patterns between conventional etching using HF and MEP, MEP generally resulted in a less roughened surface than HF etching [40]. In prosthodontic studies, MEP showed good long-term bonding properties on different ceramic materials [31, 41]. However, very little clinical data on MEP are currently available. Two studies showed satisfactory results for this adhesive after 6 months of clinical testing [41, 42], but further studies are needed to confirm these outcomes. The authors are aware of only one further study on MEP in orthodontic research with respect to milled silicate ceramic restorations. Similar to our findings González-Serrano et al. described lower SBS values after conditioning of LiSi with MEP in comparison to HF, but the differences were not significant after $24 \mathrm{~h}$. They also found a very little reduction of SBS after HF treatment and thermal cycling, but a significant reduction after MEP pretreatment [43]. In contrast to our finding, Duygu et al. reported slightly higher SBS values after pretreatment of LEU with MEP in comparison to HF
Table 4 Distribution of ARI. Number and percentage of specimen and the rated ARI score $(0-3)$. Data are given for every surface and the respective pretreatment separately and for all specimens together

\begin{tabular}{lllllll}
\hline Surface & Pretreatment & \multicolumn{2}{l}{ ARI } & & Total \\
\cline { 3 - 6 } & & $\mathbf{0}$ & $\mathbf{1}$ & $\mathbf{2}$ & $\mathbf{3}$ \\
\hline LEU & $\mathrm{HF}$ & $0(0.0 \%)$ & $1(2.2 \%)$ & $1(2.2 \%)$ & $43(95.6 \%)$ & $45(100 \%)$ \\
& $\mathrm{MEP}$ & $19(42.2 \%)$ & $15(33.3 \%)$ & $4(8.9 \%)$ & $7(15.6 \%)$ & $45(100 \%)$ \\
& $\mathrm{CoJet}$ & $0(0.0 \%)$ & $1(2.2 \%)$ & $5(11.1 \%)$ & $39(86.7 \%)$ & $45(100 \%)$ \\
& $\mathrm{SiC}$ & $0(0.0 \%)$ & $2(4.4 \%)$ & $10(22.2 \%)$ & $33(73.3 \%)$ & $45(100 \%)$ \\
LiSi & $\mathrm{HF}$ & $0(0.0 \%)$ & $2(4.4 \%)$ & $8(17.8 \%)$ & $35(77.8 \%)$ & $45(100 \%)$ \\
& $\mathrm{MEP}$ & $15(33.3 \%)$ & $14(31.1 \%)$ & $2(4.4 \%)$ & $14(31.1 \%)$ & $45(100 \%)$ \\
& $\mathrm{CoJet}$ & $3(6.7 \%)$ & $13(28.9 \%)$ & $6(13.3 \%)$ & $23(51.1 \%)$ & $45(100 \%)$ \\
& $\mathrm{SiC}$ & $23(51.1 \%)$ & $12(26.7 \%)$ & $3(6.7 \%)$ & $7(15.6 \%)$ & $45(100 \%)$ \\
Enamel & $\mathrm{H}_{3} \mathrm{PO} \mathrm{H}_{4}$ & $3(6.7 \%)$ & $13(28.9 \%)$ & $10(22.2 \%)$ & $19(42.2 \%)$ & $45(100 \%)$ \\
Total & & $63(15.6 \%)$ & $73(18.0 \%)$ & $49(12.1 \%)$ & $220(54.3 \%)$ & $405(100 \%)$ \\
\hline
\end{tabular}

$\mathrm{HF}$ hydrofluoric acid, $\mathrm{MEP}$ Monobond Etch\&Prime, $\mathrm{SiC}$ silicium carbide, $\mathrm{LiSi}$ lithium disilicate, $\mathrm{H}_{3} \mathrm{PO}_{4}$ phosphoric acid 
Fig. 3 Scanning electron micrographs of the bonding areas on the ceramic surface after SBS measurement. General views at 30-fold magnification. Trapezoidal bonding areas with no attachment material left $(\mathbf{C}$, $\mathbf{G}$, and $\mathbf{K})$ or all $(\mathbf{A}, \mathbf{I}$, and $\mathbf{M})$ or almost all (E) of the attachment material left (left column). Close up views (250-fold) of the corresponding bonding area. A rough surface of the attachment material is discernible $(\mathbf{B}, \mathbf{F}$, $\mathbf{J}$, and $\mathbf{N}$ ) (right column). The ceramic surfaces show very little $(\mathbf{H})$, some $(\mathbf{D})$, and many scratches (L). A and B LEU/ HF. C and D LEU/MEP. E and F LEU/CoJet. $\mathbf{G}$ and $\mathbf{H} \mathrm{LiSi} /$ MEP. I and $\mathbf{J} \mathrm{LiSi} / \mathrm{CoJet} . \mathbf{K}$ and L LiSi/SiC. M and $\mathbf{N}$ Enamel/ phosphoric acid. $L E U$ leucite, LiSi lithium disilicate, $H F$ hydrofluoric acid, MEP Monobond Etch\&Prime, $\mathrm{SiC}$ grinder silicium carbide grinder, $\mathrm{H}_{3} \mathrm{PO}_{4}$ phosphoric acid
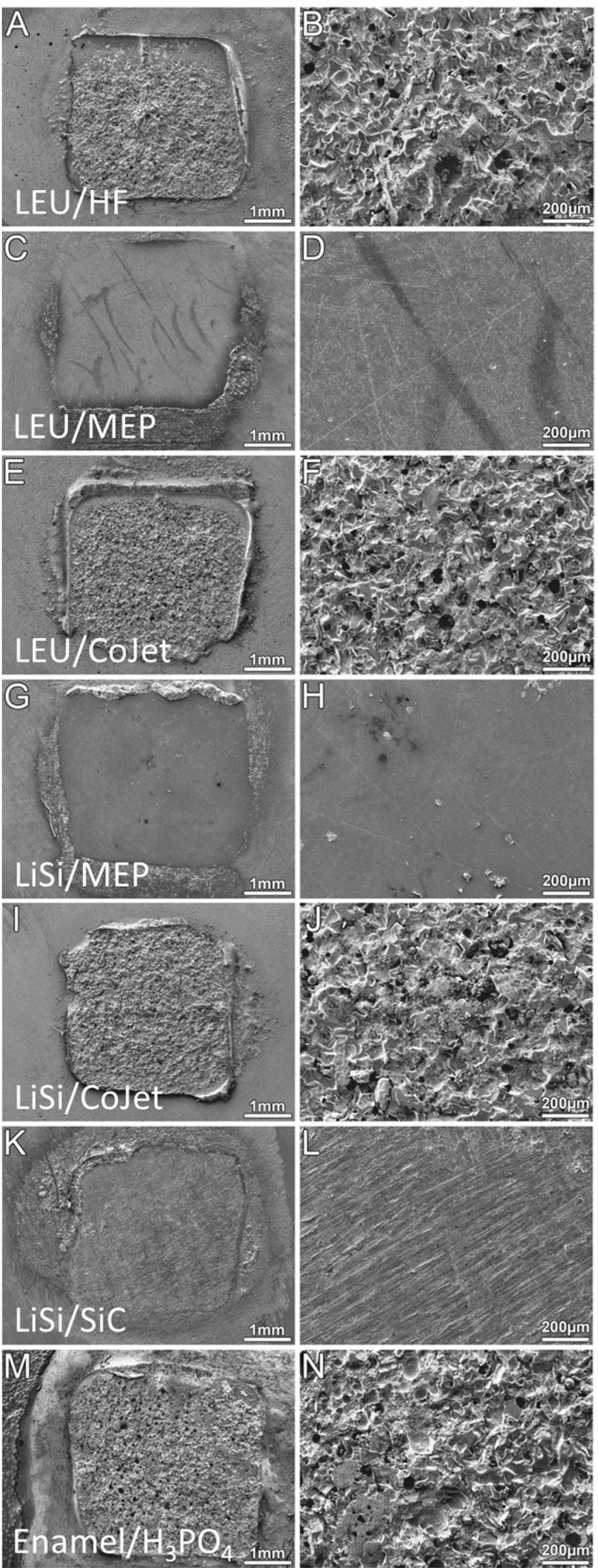
[44]. Many studies comparing different pretreatment methods used airborne particle abrasion with alumina powder as an alternative for HF $[45,46]$. With this kind of pretreatment there is a considerable risk to generate cracks in the ceramic. Therefore, ceramic specimens were pretreated with silica-coated aluminum oxide (CoJet) in the present study since due the coating with silica the particles are round without sharp-edged areas that could damage the ceramic [47]. Karan et al. reported similar SBS values after pretreatment of different silicate ceramics with either CoJet or $50-\mu \mathrm{m}$ aluminia oxide sandblasting followed by $\mathrm{HF}$ and thermo cycling [48]. In a further investigation pretreatment of LEU with CoJet resulted in significant higher SBS values after thermal cycling compared to HF [49], and slightly higher after $24 \mathrm{~h}$ [44] which is in accordance with the present results, although the difference we found were not significant. All of the above described studies used metal brackets and not ceramic, as in the present investigation. Therefore, comparisons should be made with caution and especially SBS values cannot be compared. In prosthetic dentistry $\mathrm{SiC}$ grinders and silane (Cimara system) is one of the recommended possibilities for intraoral reparation of ceramic restorations [50]. The authors are not aware of any study investigating the use of $\mathrm{SiC}$ grinders (Cimara system) for orthodontic purposes and therefore the results cannot be compared. The present results indicate that $\mathrm{SiC}$ grinders can be recommended only for the pretreatment of LEU, as the SBS values of LiSi and the brackets were not sufficiently high after 90 days of wet storage.

The second hypothesis "the aging level shows no impact on SBS values" was rejected. While all ceramic specimens pretreated with HF and LEU specimens pretreated with SiC presented no impact of aging, pretreatment with MEP or CoJet led to a decrease or increase of SBS values. In this study, the specimens were tested initially, aged for 90 days in distilled water or aged for 500 cycles in accordance with DIN 13,990:2017-04 [33] in a thermocycling machine, which corresponds to a period of approximately 4-6 months in vivo [51,52]. Thermocycling means a repeated cycling between two temperatures $\left(5\right.$ and $55^{\circ} \mathrm{C}$ ) subject to an adequate dwelling time (20 s) to ensure thermal adjustment of the specimens without an exposure to extreme thermal stress [53]. Our measured bond strength results showed an effect only for pretreatment with MEP, regardless of the used silicate ceramic. Other studies also observed an impact of thermocycling on bond strength $[54,55]$. Although in-vitro thermocycling subjects all specimens to standardized and reproducible stress, there is no systematic standard procedure for subjecting materials to cycling regimens at present. Thermal loading may lead to mechanical stress at the bonding area, causing volumetric changes. Nevertheless, thermal aging is usually still not used in numerous orthodontic bond strength tests [44, 45, 56, 57]. Ninety days of wet storage resulted in decreased SBS values between the bracket and LiSi after pretreatment with CoJet. These values were still sufficiently high for clinical use, in contrast to the SiC-pretreated LiSi. The decrease in SBS values is likely to be caused by hydrolysis, degradation of fillers, and softening [58]. The results of the present study show that in SBS testing aging in wet environment is strongly recommended to be included in addition to thermal cycling and the initial measurement. To the best of the authors' knowledge this aspect has not been considered in any orthodontic SBS study before.

The third hypothesis "the choice of silicate ceramic shows no impact on SBS values" was rejected as well. The influence of the ceramic type was most obvious after 90 days of storage, within specimens pretreated with $\mathrm{SiC}$; SBS values were below clinically acceptable limits, when brackets were bonded to LiSi. SBS values of LiSi were also decreased after CoJet application. The elastic modulus of LiSi is higher compared to LEU (approximately $95 \mathrm{GPa}$ vs. $80 \mathrm{GPa}$ ). As a consequence, there is a higher risk for cracks during mechanical pretreatment where water is likely to be absorbed during wet storage resulting in lower SBS values. In contrast initial values were higher for $\mathrm{LiSi}$ after the use of HF and MEP likely due to higher surface roughness values after etching.

The results of the evaluation of the ARI are in accordance with the SBS values. An ARI of 3 ("all of the attachment material left on the ceramic") was most common in those groups with higher SBS values (HF, CoJet, and $\mathrm{SiC}$ on LEU), whereas lower ARI was present in those groups with lower values such as MEP. In general, in the present study SBS values were remarkably high (median: $33.6 \mathrm{MPa}$ ). This might be explained by the fact that ceramic brackets were bonded to ceramic surfaces [59]. Al-Hity et al. found significant higher tensile bond strength values for ceramic brackets bonded to glass ceramic in comparison to metal brackets [2]. Conversely, this does not mean that due to these high values and the high presence of an ARI 3 there must be a high risk of damaging the ceramic surface during debonding of the brackets. Considering that in the shear bond strength testing device the debonding load is applied in only one direction (occlusal-gingival) whereas the ceramic bracket used in this investigation has an integrated stress concentrator that makes debonding by a gentle squeezing with the corresponding plier very simple. Most other ceramic brackets have special debonding mechanisms as well, and the force applied in the testing device is not comparable in any way to the in-vivo debonding mechanism. This is a considerable disadvantage of SBS testing, and evaluation of ARI and clinical consequences should be drawn very carefully. Initial SBS values between the bracket and enamel showed the highest values and decreased due to artificial aging, comparable to pretreatment with HF. Therefore, it can be assumed that bonding 
between ceramic surfaces and ceramic brackets can be as reliable as between human enamel and ceramic brackets.

In summary, despite some differences, almost all SBS values in the present investigation were above the required 5-10 MPa, with exception of the SiC-pretreated LiSi after 90 days of storage. Due to its in-vitro character and therefore the absence of saliva and chewing force as well as force exerted by an orthodontic wire SBS testing has several limitations. As the force is only applied from one direction the shear stress is very likely not uniform across the whole interface. Therefore, it might be advantageous reporting the debonding force under shear loading conditions. Bishara et al. reported a study setup in which the debonding force was applied via a plier from two sides of the bracket base, similar to the clinical application [60]. But most studies in the literature still use the classical SBS testing setting and also report SBS values, which is to date also recommended by the DIN 13,990:2017-04 [33]. Furthermore, results of different studies are difficult to compare due to various experimental setups. In the present study different pretreatment methods were compared to a method that has been successfully applied in clinical treatment. Therefore, the results are of clinical relevance as they can be related to a method that is already used providing a reliable basis for clinical trials, although the absolute values are not transferable to a clinical setup.

\section{Conclusion}

Within the limitations of this in-vitro study, the following conclusions were drawn:

- The intraoral application of HF for orthodontic bonding is not necessary.

- CoJet and MEP are considerable pretreatment methods to bond ceramic brackets to silicate ceramics.

- $\mathrm{SiC}$ grinders should only be used for LEU pretreatment.

- Bonding on enamel presented higher or comparable values compared to bonding on ceramic restorations.

Acknowledgements The authors appreciate the material support given by $3 \mathrm{M}$, Ivoclar Vivadent, VITA Zahnfabrik, and VOCO

Author contribution Rebecca Jungbauer, Christian Kirschneck, Peter Proff, Daniel Edelhoff, and Bogna Stawarczyk contributed to the study conception and design. Material preparation, data collection, and analysis were performed by Rebecca Jungbauer, Christian Hammer, and Bogna Stawarczyk. The first draft of the manuscript was written by Rebecca Jungbauer and Bogna Stawarczyk, and all authors commented on previous versions of the manuscript. All authors read and approved the final manuscript.
Funding Open Access funding enabled and organized by Projekt DEAL.

\section{Declarations}

Ethical approval The collection and use of human teeth, which were extracted for medical reasons, was approved by the ethics committee of the University of Regensburg, Germany (12-170-0150).

Informed consent From all participants or their parent/legal guardian informed consent was obtained.

Conflict of interest The authors declare no competing interests.

Open Access This article is licensed under a Creative Commons Attribution 4.0 International License, which permits use, sharing, adaptation, distribution and reproduction in any medium or format, as long as you give appropriate credit to the original author(s) and the source, provide a link to the Creative Commons licence, and indicate if changes were made. The images or other third party material in this article are included in the article's Creative Commons licence, unless indicated otherwise in a credit line to the material. If material is not included in the article's Creative Commons licence and your intended use is not permitted by statutory regulation or exceeds the permitted use, you will need to obtain permission directly from the copyright holder. To view a copy of this licence, visit http://creativecommons.org/licenses/by/4.0/.

\section{References}

1. Pannes DD, Bailey DK, Thompson JY et al (2003) Orthodontic bonding to porcelain: a comparison of bonding systems. J Prosthet Dent 89:66-69. https://doi.org/10.1067/mpr.2003.63

2. Al-Hity R, Gustin M-P, Bridel N et al (2012) In vitro orthodontic bracket bonding to porcelain. Eur J Orthod 34:505-511. https:// doi.org/10.1093/ejo/cjr043

3. Reynolds IR (1975) Letter: "Composite filling materials as adhesives in orthodontics." Br Dent J 138:83

4. Jerman E, Lümkemann N, Eichberger M et al (2021) Evaluation of translucency, Marten's hardness, biaxial flexural strength and fracture toughness of 3Y-TZP, 4Y-TZP and 5Y-TZP materials. Dent Mater 37:212-222. https://doi.org/10.1016/j.dental.2020.11. 007

5. Stawarczyk B, Awad D, Ilie N (2016) Blue-light transmittance of esthetic monolithic CAD/CAM materials with respect to their composition, thickness, and curing conditions. Oper Dent 41:531540. https://doi.org/10.2341/15-252-L

6. Höland W, Schweiger M, Frank M et al (2000) A comparison of the microstructure and properties of the IPS Empress 2 and the IPS Empress glass-ceramics. J Biomed Mater Res 53:297-303. https://doi.org/10.1002/1097-4636(2000)53:4\%3c297:aid-jbm3\% 3e3.0.co;2-g

7. Della Bona A, Mecholsky JJ, Anusavice KJ (2004) Fracture behavior of lithia disilicate- and leucite-based ceramics. Dent Mater 20:956-962. https://doi.org/10.1016/j.dental.2004.02.004

8. Buso L, Oliveira-Júnior OB, Hiroshi Fujiy F et al (2011) Biaxial flexural strength of CAD/CAM ceramics. Minerva Stomatol 60:311-319

9. Tavas MA, Watts DC (1989) The use of a cone and plate viscometer for determination of flow properties of unfilled resins and etching gels. J Oral Rehabil 16:185-192. https://doi.org/10.1111/j. 1365-2842.1989.tb01332.x 
10. Oh W-S, Shen C, Alegre B et al (2002) Wetting characteristic of ceramic to water and adhesive resin. J Prosthet Dent 88:616-621. https://doi.org/10.1067/mpr.2002.129805

11. Phoenix RD, Shen C (1995) Characterization of treated porcelain surfaces via dynamic contact angle analysis. Int J Prosthodont 8:187-194

12. Lee-Knight C, Wylie SG, Major PW et al (1997) Mechanical and electrothermal debonding: effect on ceramic veneers and dental pulp. Am J Orthod Dentofacial Orthop 112:263-270. https://doi. org/10.1016/S0889-5406(97)70254-3

13. Gillis I, Redlich M (1998) The effect of different porcelain conditioning techniques on shear bond strength of stainless steel brackets. Am J Orthod Dentofacial Orthop 114:387-392

14. Matos NRSd, Costa AR, Valdrighi HC et al (2016) Effect of acid etching, silane and thermal cycling on the bond strength of metallic brackets to ceramic. Braz Dent J 27:734-738. https://doi.org/ 10.1590/0103-6440201601077

15. Costa AR, Correr AB, Puppin-Rontani RM et al (2012) Effect of bonding material, etching time and silane on the bond strength of metallic orthodontic brackets to ceramic. Braz Dent J 23:223-227

16. Di Guida LA, Benetti P, Corazza PH et al (2019) The critical bond strength of orthodontic brackets bonded to dental glass-ceramics. Clin Oral Investig. https://doi.org/10.1007/s00784-019-02881-5

17. Wood DP, Jordan RE, Way DC et al (1986) Bonding to porcelain and gold. Am J Orthod 89:194-205. https://doi.org/10.1016/00029416(86)90032-1

18. Shimada Y, Yamaguchi S, Tagami J (2002) Micro-shear bond strength of dual-cured resin cement to glass ceramics. Dent Mater 18:380-388

19. Brentel AS, Ozcan M, Valandro LF et al (2007) Microtensile bond strength of a resin cement to feldpathic ceramic after different etching and silanization regimens in dry and aged conditions. Dent Mater 23:1323-1331. https://doi.org/10.1016/j.dental.2006.11. 011

20. Spohr AM, Sobrinho LC, Consani S et al (2003) Influence of surface conditions and silane agent on the bond of resin to IPS Empress 2 ceramic. Int J Prosthodont 16:277-282

21. Kitayama S, Nikaido T, Takahashi R et al (2010) Effect of primer treatment on bonding of resin cements to zirconia ceramic. Dent Mater 26:426-432. https://doi.org/10.1016/j.dental.2009.11.159

22. Grewal Bach GK, Torrealba Y, Lagravère MO (2014) Orthodontic bonding to porcelain: a systematic review. Angle Orthod 84:555560. https://doi.org/10.2319/083013-636.1

23. Stawarczyk B, Hristova E, Sener B, Roos M, Edelhoff D, Keul C (2014) Effect of hydrofluoric acid etching duration on fracture load and surface properties of three CAD/CAM glass-ceramics. Oral Health Dent Manag 13:1131-1139

24. Zachrisson BJ (1977) A posttreatment evaluation of direct bonding in orthodontics. Am J Orthod 71:173-189

25. Ozcan M, Allahbeickaraghi A, Dündar M (2012) Possible hazardous effects of hydrofluoric acid and recommendations for treatment approach: a review. Clin Oral Investig 16:15-23. https://doi. org/10.1007/s00784-011-0636-6

26. Jochen DG (1973) Repair of fractured porcelain denture teeth. J Prosthet Dent 29:228-230. https://doi.org/10.1016/0022-3913(73) 90119-4

27. Barbosa VLT, Almeida MA, Chevitarese O et al (1995) Direct bonding to porcelain. Am J Orthod Dentofacial Orthop 107:159 164. https://doi.org/10.1016/S0889-5406(95)70131-1

28. Litovitz TL, Klein-Schwartz W, Dyer KS et al (1998) 1997 annual report of the American Association of Poison Control Centers Toxic Exposure Surveillance System. Am J Emerg Med $16: 443-497$

29. Naseh R, Afshari M, Shafiei F et al (2018) Shear bond strength of metal brackets to ceramic surfaces using a universal bonding resin. J Clin Exp Dent 10:e739-e745. https://doi.org/10.4317/jced. 54175

30. Wiedenmann F, Klören M, Edelhoff D et al (2021) Bond strength of CAD-CAM and conventional veneering materials to different frameworks. J Prosthet Dent 125:664-673. https://doi.org/10. 1016/j.prosdent.2020.01.048

31. Liebermann A, Detzer J, Stawarczyk B (2019) Impact of recently developed universal adhesives on tensile bond strength to computer-aided design/manufacturing ceramics. Oper Dent 44:386395. https://doi.org/10.2341/18-017-L

32. Kramer MR, Edelhoff D, Stawarczyk B (2016) Flexural strength of preheated resin composites and bonding properties to glassceramic and dentin. Materials (Basel) 9(2):83. https://doi.org/10. 3390/ma9020083

33. DIN 13990:2017-04 Zahnheilkunde - Prüfverfahren für die Scherhaftfestigkeit von Adhäsiven für kieferorthopädische Befestigungselemente

34. Ebert T, Elsner L, Hirschfelder U et al (2016) Shear bond strength of brackets on restorative materials: comparison on various dental restorative materials using the universal primer Monobond® Plus. J Orofac Orthop 77:73-84. https://doi.org/10.1007/ s00056-016-0011-y

35. Knaup T, Korbmacher-Steiner H, Jablonski-Momeni A (2021) Der Einfluss des kariesprotektiven Peptids P11-4 auf den Haftverbund zwischen Metallbracket und Zahnschmelz (Effect of the caries-protective self-assembling peptide P11-4 on shear bond strength of metal brackets). J Orofac Orthop 82:329-336. https://doi.org/10.1007/s00056-020-00247-1

36. Korbmacher H, Klocke A, Huck L et al (2002) Enamel conditioning for orthodontic bonding with a single-step bonding agent. J Orofac Orthop 63:463-471. https://doi.org/10.1007/ s00056-002-0130-5

37. Hannig C, Hahn P, Thiele P-P et al (2003) Influence of different repair procedures on bond strength of adhesive filling materials to etched enamel in vitro. Oper Dent 28:800-807

38. Artun J, Bergland S (1984) Clinical trials with crystal growth conditioning as an alternative to acid-etch enamel pretreatment. Am J Orthod 85:333-340

39. Landis JR, Koch GG (1977) The measurement of observer agreement for categorical data. Biometrics 33:159-174

40. El-Damanhoury HM, Gaintantzopoulou MD (2017) Self-etching ceramic primer versus hydrofluoric acid etching: etching efficacy and bonding performance. J Prosthodont Res. https://doi. org/10.1016/j.jpor.2017.06.002

41. Román-Rodríguez J-L, Perez-Barquero J-A, Gonzalez-Angulo E et al (2017) Bonding to silicate ceramics: conventional technique compared with a simplified technique. J Clin Exp Dent 9:e384-e386. https://doi.org/10.4317/jced.53570

42. Siqueira F, Cardenas AM, Gutierrez MF et al (2016) Laboratory performance of universal adhesive systems for luting CAD/ CAM restorative materials. J Adhes Dent 18:331-340. https:// doi.org/10.3290/j.jad.a36519

43. González-Serrano C, Phark J-H, Fuentes MV et al (2020) Effect of a single-component ceramic conditioner on shear bond strength of precoated brackets to different CAD/CAM materials. Clin Oral Investig. https://doi.org/10.1007/s00784-020-03504-0

44. Duygu R, Bengisu Y, Eman O et al (2021) Bond strength of metal brackets to feldspathic ceramic treated with different surface conditioning methods: an in vitro study. Eur Oral Res 55 1:7. https://doi.org/10.26650/eor.20210004

45. Kocadereli I, Canay S, Akça K (2001) Tensile bond strength of ceramic orthodontic brackets bonded to porcelain surfaces. Am J Orthod Dentofacial Orthop 119:617-620. https://doi.org/10. $1067 / \bmod .2001 .113655$ 
46. Falkensammer F, Freudenthaler J, Pseiner B et al (2012) Influence of surface conditioning on ceramic microstructure and bracket adhesion. Eur J Orthod 34:498-504. https://doi.org/10. 1093/ejo/cjr034

47. Kelch M, Schulz J, Edelhoff D et al (2019) Impact of different pretreatments and aging procedures on the flexural strength and phase structure of zirconia ceramics. Dent Mater 35:1439-1449. https://doi.org/10.1016/j.dental.2019.07.020

48. Karan S, Büyükyilmaz T, Toroğlu MS (2007) Orthodontic bonding to several ceramic surfaces: are there acceptable alternatives to conventional methods? Am J Orthod Dentofacial Orthop 132:144.e7-14. https://doi.org/10.1016/j.ajodo.2006.12.006

49. Zhang Z-C, Qian Y-F, Yang Y-M et al (2016) Haftfestigkeit von mit lichtgehärtetem Adhäsiv auf silikatbasierter Keramik aufgebrachten Metallbrackets: Einfluss unterschiedlicher Methoden zur Oberflächenbehandlung (Bond strength of metal brackets bonded to a silica-based ceramic with light-cured adhesive: influence of various surface treatment methods). J Orofac Orthop 77:366-372. https://doi.org/10.1007/s00056-016-0044-2

50. Gul P, Altınok-Uygun L (2020) Repair bond strength of resin composite to three aged CAD/CAM blocks using different repair systems. J Adv Prosthodont 12:131-139. https://doi.org/10. 4047/jap.2020.12.3.131

51. Pröbster L, Maiwald U, Weber H (1996) Three-point bending strength of ceramics fused to cast titanium. Eur J Oral Sci 104:313-319. https://doi.org/10.1111/j.1600-0722.1996.tb000 83. $\mathrm{x}$

52. Leibrock A, Degenhart M, Behr M et al (1999) In vitro study of the effect of thermo- and load-cycling on the bond strength of porcelain repair systems. J Oral Rehabil 26:130-137. https://doi. org/10.1046/j.1365-2842.1999.00346.x

53. Hancox NL (1998) Thermal effect on polymer matrix composites: part 1. Thermal cycling Mater Design 19:85-91
54. Holderegger C, Sailer I, Schuhmacher C et al (2008) Shear bond strength of resin cements to human dentin. Dent Mater 24:944950. https://doi.org/10.1016/j.dental.2007.11.021

55. Mazzitelli C, Monticelli F, Toledano M et al (2012) Effect of thermal cycling on the bond strength of self-adhesive cements to fiber posts. Clin Oral Investig 16:909-915. https://doi.org/10. 1007/s00784-011-0576-1

56. Stella JPF, Oliveira AB, Nojima LI et al (2015) Four chemical methods of porcelain conditioning and their influence over bond strength and surface integrity. Dental Press J Orthod 20:51-56. https://doi.org/10.1590/2176-9451.20.4.051-056.oar

57. Mehta AS, Evans CA, Viana G et al (2016) Bonding of metal orthodontic attachments to sandblasted porcelain and zirconia surfaces. Biomed Res Int 2016:5762785. https://doi.org/10.1155/ 2016/5762785

58. Weir MD, Moreau JL, Levine ED et al (2012) Nanocomposite containing $\mathrm{CaF}(2)$ nanoparticles: thermal cycling, wear and longterm water-aging. Dent Mater 28:642-652. https://doi.org/10. 1016/j.dental.2012.02.007

59. Labunet A, Kui A, Voina-Tonea A et al (2021) Orthodontic attachment adhesion to ceramic surfaces. Clin Cosmet Investig Dent 13:83-95. https://doi.org/10.2147/CCIDE.S302770

60. Bishara SE, Fonseca JM, Fehr DE et al (1994) Debonding forces applied to ceramic brackets simulating clinical conditions. Angle Orthod 64:277-282. https://doi.org/10.1043/0003-3219(1994) 064\%3c0277:DFATCB\%3e2.0.CO;2

Publisher's note Springer Nature remains neutral with regard to jurisdictional claims in published maps and institutional affiliations. 